\title{
Canadian Digestive Diseases Week (CDDW) 2004
}

\author{
Desmond Leddin MB FRCPC \\ CAG President-Elect \& CDDW Implementation Committee Chair
}

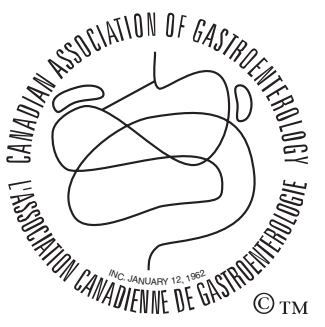

En français voir page 620
$\mathrm{P}$ lanning is well underway for CDDW 2004, which will be held in Banff, Alberta, February 27 to March 1, 2004. A major difference this year is that instead of running from Saturday to Wednesday, the meeting will begin on Friday evening and conclude mid-day on Monday. This change is in response to feedback from community-based members who indicated that a meeting scheduled over the weekend would prove less disruptive to their office practice. If the new format is successful, consideration may have to be given to renaming the conference Canadian Digestive Diseases Weekend!

This year the goal is simple: to run the best, intimate program possible for the membership, whether their background is in clinical practice, science or liver diseases. We will continue to build on the advantage of the relatively small size of CDDW to run highly interactive, small group sessions.

\section{CLINICAL PROGRAM}

CDDW begins late Friday afternoon (Figure 1) with a poster session followed by the RD McKenna Memorial Lectureship evening, the traditional kick-off to our annual conference. The heart of the program runs all day on Saturday and Sunday, with the CAG/CASL Postgraduate Course winding up the conference on Monday morning. Here is a quick look at just a few of the sessions being offered:

\section{Symposia}

- Breakfast with the Experts: This is a small-group interactive learning opportunity. The 2004 program has been expanded to address two topics - inflammatory bowel disease (IBD) and liver disease. These two sessions will run concurrently on Saturday and Sunday morning. Please note that on-site preregistration is required due to space limitations.

- Advances in Delivery of Care: The health care system is changing; nurse practitioners and endoscopists, new methods of payment, and other forces will change the practice of gastroenterology. What does this mean for the practicing gastroenterologist?
- Colonoscopy - Who Needs It?: A critical look at the most common procedure in gastroenterology. This program builds on the success of last year's look at upper gastrointestinal endoscopy.

- Advances in Therapeutics (luminal): This session will explore the areas of upper gastrointestinal bleeding, NSAIDs, and COX-2 inhibitors.

- In My Practice: This case-based, interactive session was ranked the highest of all at the 2003 meeting. Therefore, in 2004 we have expanded it to two sessions - one on liver and one on IBD. Based on real cases and presented by experienced clinicians who are national and international experts, the emphasis is on interaction with the audience. Don't miss this chance to watch the evidence meet the street!

- The Postgraduate Course: The course focuses on what is cutting edge in a format of short presentations. In 2004, the focus will be on pancreatic diseases, nutrition and liver disease.

- The CAG/CDHF guidelines on colon cancer screening: Finally, a Canadian position on an issue which is of importance to all. These will be rolled out and discussed as part of the Postgraduate Course.

- The Best in Clinical Research: This year, the research committee has created a new paper session with a focus on clinical research. Take this opportunity to see where the country's best clinical researchers are heading.

- Paediatrics: Integrated into all of the symposia and sessions, there is much here for the pediatric gastroenterologist.

\section{Research program}

- Colorectal Cancer - New Molecular, Cellular and Environmental Paradigms: This symposium brings you state-of-the-art basic science related to colon cancer. A

Division of Gastroenterology, Victorial General Hospital Site, Halifax, Nova Scotia

Correspondence: Dr Desmond Leddin, Division of Gastroenterology, Room 912, Victoria Building, Victoria General Hosptial Site, 1278 Tower Road, Halifax, Nova Scotia B3H 2 Y9

The CAG is proud to acknowledge its Benefactor Corporate Sponsors:
Abbott Laboratories Ltd.
AstraZeneca Canada Inc.
Axcan Pharma Inc.
Janssen-Ortho Inc. 


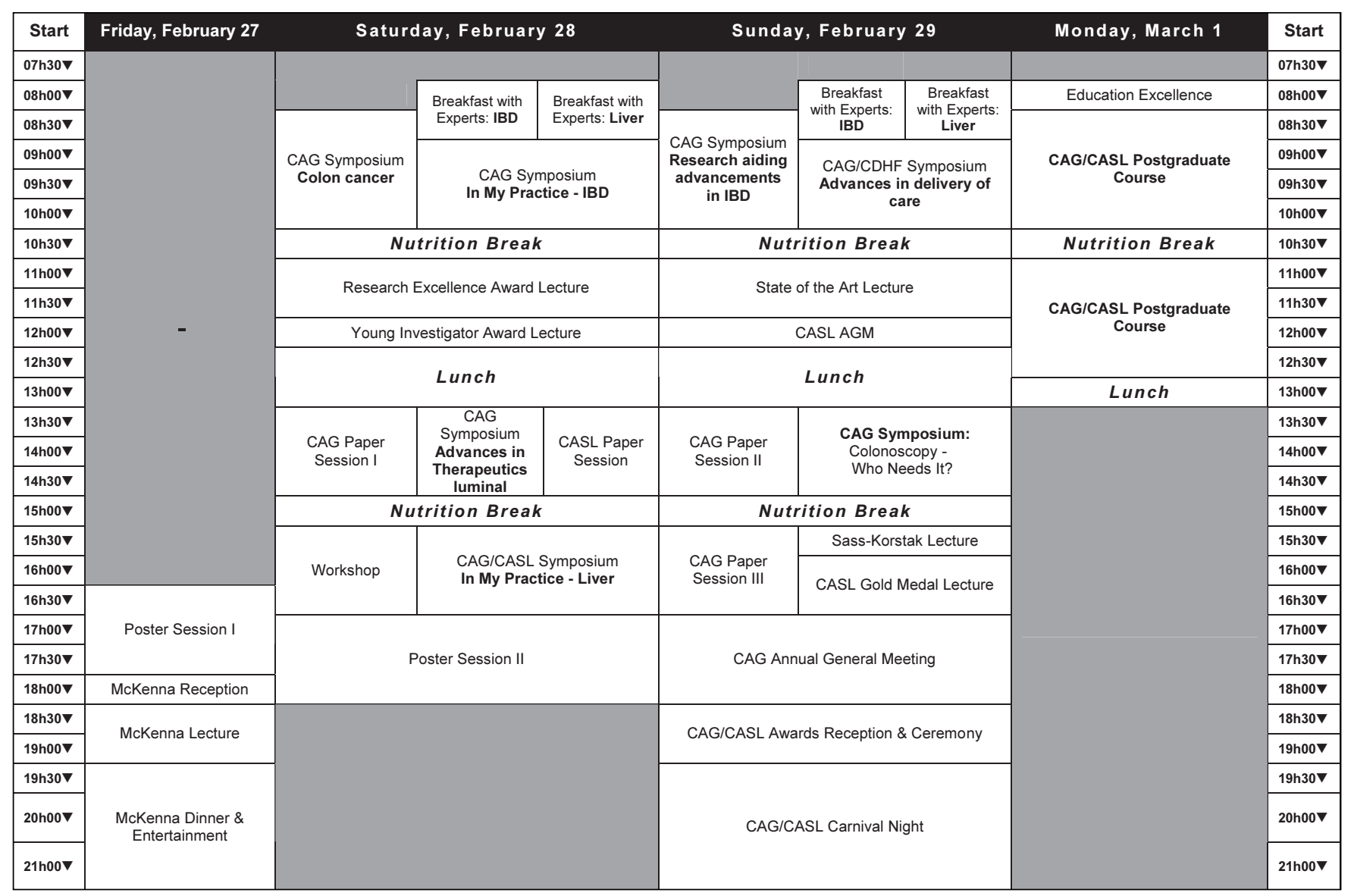

Figure 1) Canadian Digestive Diseases Week 2004 schedule

panel of international experts will present recent advances and future directions.

- Research Aiding Advancements in IBD: In recent years there has been great progress in the understanding of IBD. How will advances in the science of IBD change our management of this common disease?

- CAG Paper and Poster Sessions - Research presentations of the best basic and clinical science. In 2004, the poster sessions have been designed to permit as much interaction as possible. A new clinical science paper session will appeal to both clinicians and scientists.

\section{CASL}

- Breakfast with the Experts: Focusing on decompensated liver disease, this session promises to be an interactive, practical opportunity to learn from the best.

- CASL Papers and Posters: The premier venue for the presentation of Canadian clinical and basic science of liver disease.

- In My Practice - Liver: Building on the success of the 2003 event, which focused on luminal topics, this session will bring together clinicians and clinical scientists with the focus on management of common liver conditions.

- Sass-Korstak and CASL Gold Medal: Two prestigious lectureships which will appeal to all - scientists and clinicians.
- Postgraduate Course: CASL and CAG work together to bring the latest advances in liver and luminal disease.

\section{Social}

Where else do you get a chance to with meet all of your colleagues? One of the attractions of CDDW is the opportunity to meet old friends, make some new colleagues, and do some business. This year we are also rearranging the timing of the CAG Board Meeting to permit CAG committees to meet and set their agenda for 2004/2005.

\section{MOCERT}

Appropriate sessions of the CDDW program will be accredited (section 1) by the CAG as defined by the Maintenance of Certification Program of the Royal College of Physicians and Surgeons of Canada. A chance to rack up some serious MOCERT credits!

\section{REGISTRATION AND ACCOMMODATION}

Registration and hotel accommodation for the meeting is available on the CAG website at http://www.cag-acg.org. CDDW registration is free for Regular, Trainee, Senior, and Supporting Members of the CAG. A reduced registration fee applies for Affliliate/International Members CAG Members and for CASL members. Non-members are required to pay a registration fee of $\$ 500$. 


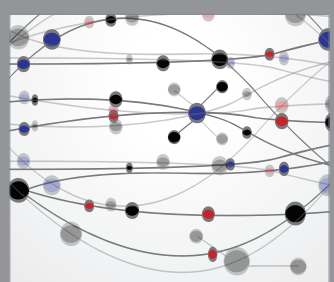

The Scientific World Journal
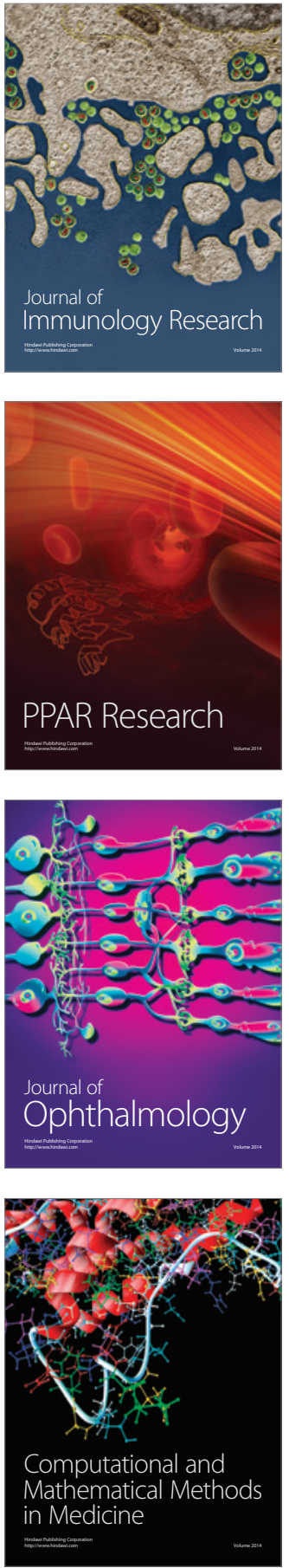

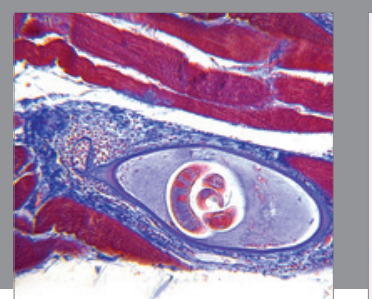

Gastroenterology Research and Practice

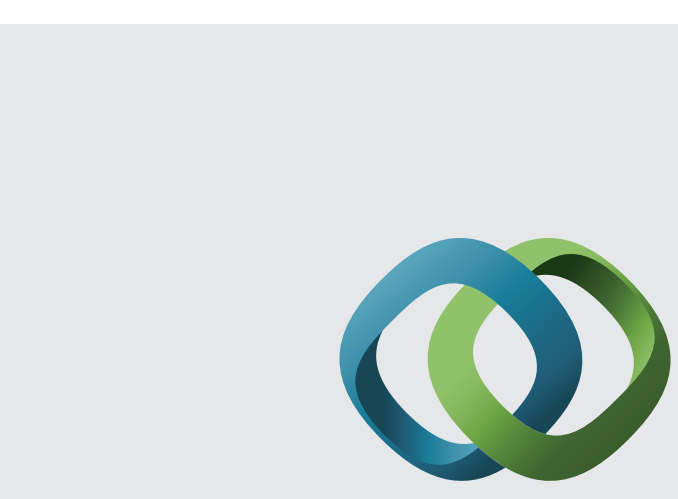

\section{Hindawi}

Submit your manuscripts at

http://www.hindawi.com
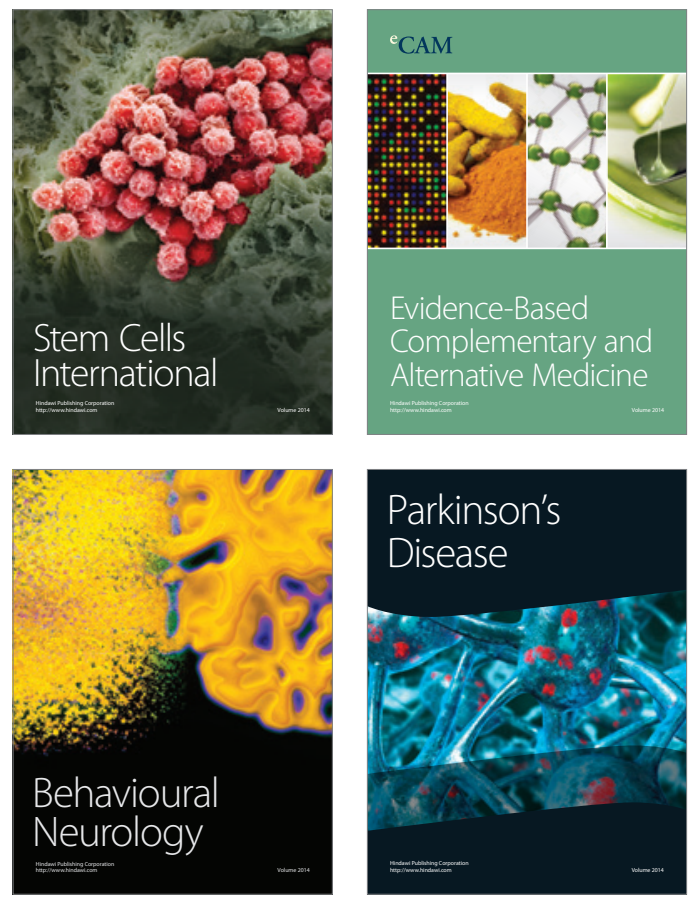
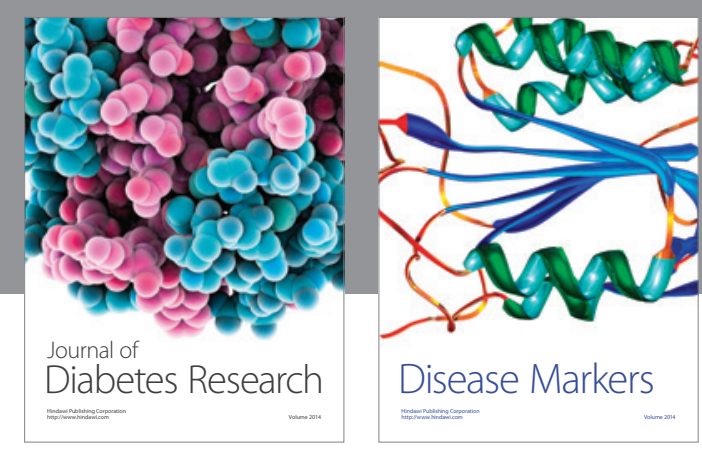

Disease Markers
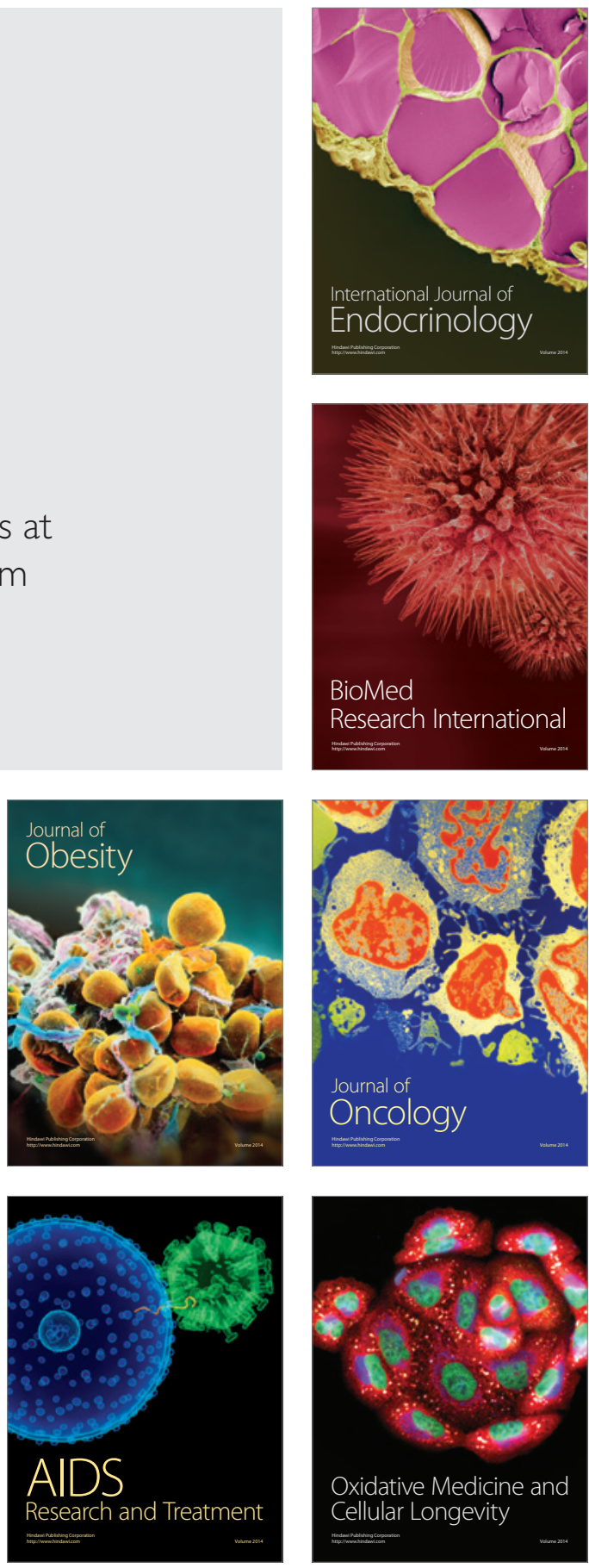